\title{
Factors predicting cases with unexpected clinical findings at necropsy
}

\author{
I A Robinson, N J E Marley
}

\begin{abstract}
Aims/background-A major medical role for postmortem examinations is the detection of clinically unexpected disease processes contributing to death. The aim of the present study was to determine whether simple clinical parameters can predict the presence of important unanticipated findings at necropsy.
\end{abstract}

Methods-Prospective audit of adult necropsies carried out in a single year to assess the extent of unexpected findings at necropsy, to compare these cases with non-necropsied deaths to confirm they are a similar population and to seek features that predict which cases have unexpected necropsy findings.

Results-No correlation was found between age, sex, duration of in-hospital treatment, surgical intervention, clinical speciality, or necropsy request rates and incidence of unexpected findings in 187 adult necropsies.

Conclusions-No parameters have been identified for patient selection to permit an increase in the yield of clinically unexpected findings. Until there is clear evidence that the current practice of patient selection is anything more than random, an increase in postmortem examination rates, as proposed by the Joint Working Party of the Royal College of Pathologists, the Royal College of Physicians of London and the Royal College of Surgeons of England in their report The Autospy and Audit, will increase the workload without necessarily producing a commensurate gain in knowledge.

(F Clin Pathol 1996;49:909-912)

Keywords: necropsy, audit.

Department of Pathology, Derbyshire

Royal Infirmary, London Road, Derby DE1 2QY

I A Robinson

Department of Histopathology, Michael Darmady Laboratory, Queen Alexandra Hospital, Portsmouth

N J E Marley

Correspondence to: Dr I A Robinson.

Accepted for publication 12 August 1996 of Pathologists, the Royal Colle Physicians of London and the Royal College of Surgeons of England, in their report The Autopsy and Audit, ${ }^{22}$ suggest that an additional $10 \%$ of general hospital deaths should go for College of Patholo postmortem examination for clinical audit This recommendation is being implemented in few, if any, institutions. Consequently, pathologists are performing necropsies on selected cases, usually to answer specific clinical questions. While the necropsy can answer many and varied clinical queries, the foremost consideration for each case must be establishing the disease process and mechanism of death. Other issues for consideration include the accuracy and choice of procedures used for diagnosis, the suitability of chosen treatment and the resulting outcome. These considerations are closely allied to those of audit.

Infections (especially fungal) and pulmonary emboli are recognised as some of the commoner unexpected disease processes found at necropsy. ${ }^{23}$ As yet we have little information to predict which individuals are more likely to succumb to these or other undiagnosed conditions. Were we able to do so, we could select those cases for postmortem examination which have the maximum educational potential.

\section{Methods}

Adult necropsies performed in a single year by trained and trainee pathologists were entered into this study. Necropsies on individuals brought in dead, where there was clinical uncertainty as to the cause of death, or those who died of major trauma were excluded. Both clinically requested and medicolegally directed necropsies were studied provided the clinicians could offer an opinion as to the cause of death.

In each case, at the end of the necropsy, the clinicians were contacted and invited to attend the mortuary to discuss the case and review the organs. This is the usual practice in the Portsmouth Hospitals. After the review a form was completed comparing clinical and pathological causes of death. Demographic data collected included age and sex of the patient, the clinician and specialty, the duration of inpatient treatment, whether the patient underwent surgery, and whether the clinicians attended the review. Using an established protocol ${ }^{24}$ the pathologists categorised the clinicopathological factors contributing to death. These categories include an irrevocable course of a recognised disease, unrecognised existing evidence of disease, therapeutic complications, or errors in judgement or treatment. A more detailed explanation of these categories is given by Harrison and Hourihane. ${ }^{25}$ Data on the non-necropsied patient population were obtained from the Patient Affairs Office at St Mary's Hospital, Portsmouth. Unrecognised 
Table 1 Unrecognised diseases encountered at necropsy

\begin{tabular}{ll}
\hline Disease & Number of cases (\%) \\
\hline Cancer related disease processes & $16(21)$ \\
Pulmonary emboli & $14(19)$ \\
Coronary atherosclerosis & $14(19)$ \\
Gastrointestinal & $9(12)$ \\
$\quad$ perforation/obstruction & $8(11)$ \\
Infection & $6(8)$ \\
Pancreatitis & $4(4)$ \\
Cardiomyopathy/myocarditis/valve & \\
$\quad$ abnormality & $4(4)$ \\
Ruptured aortic aneurysm & $1(1)$ \\
Cerebrovascular bleed & $1(1)$ \\
Fractured pelvis & \\
\hline
\end{tabular}

disease correlation and trends were established by $\chi^{2}$ analysis.

\section{Results}

From 20 March 1992 to 19 March 1993, 187 necropsies were performed on patients dying at St Mary's Hospital, Portsmouth. During this period there were 969 in-hospital deaths, giving a necropsy rate of $19.3 \%$. This figure of 187 necropsies represented $100 \%$ of suitable in-hospital necropsies and no case with adequate time for clinical investigation was excluded.

The clinicians attended a review of findings and discussion of the case in $72.8 \%(136 / 187)$ of cases. Reasons for not attending the review were "the team is involved with other clinical activities" (33 cases), the pathologist determined there was little or no unrecognised pathology demonstrated at necropsy (10 cases), "too far to the mortuary" (four cases), and on four other occasions we were unable to contact the clinicians.

Necropsies were performed on 109 men and 78 women. The mean age of the patients necropsied was 72.5 years ( 72.0 for men and 73.8 for women); range 35-96 years; median 75 years. This corresponded to the nonnecropsied population which had a mean age of 71.8 years with a slight preponderance of women $(52 \%)$. There was no significant difference in age and sex distribution between the necropsied and non-necropsied groups.

The overall incidence of important unexpected findings was $40.1 \%$ (75/187 necropsies) (table 1). An unexpected major finding was found in 38\% (30/78) of women compared with $41 \%(45 / 109)$ of men. Death due to unexpected atheroma, encompassing coronary artery disease, atherosclerotic aortic aneurysms and stroke (16/44 v 3/30), and pulmonary emboli $(12 / 44 v 2 / 30)$ was more common in men. Unexpected pancreatitis $(5 / 30 v 0 / 44)$ and gastrointestinal obstruction and perforation $(6 / 30 v 2 / 44)$ were more common in women. The only significant difference with regard to sex was seen with pancreatitis ( $p<$ 0.01 ).

Of those under 75 years of age, $34 \%$ had an unrecognised disease processes compared with $46 \%$ for those aged 75 or over. This was not significant and no trend for an increased likelihood of unexpected disease and age could be demonstrated.

Unexpected findings in the cancer related deaths included unrecognised cancers, incor- rectly identified primary site and unrecognised complications due to the malignant process (for example, bowel perforation due to metastases). In cancer related deaths $(n=16)$ there was a significant correlation between age and unexpected findings (three in those under 75 years of age and 13 in those aged 75 and over: $\mathrm{p}<0.01$ ). Conversely, unforeseen pulmonary emboli was encountered slightly more often in the younger age group (10 in those under 75 years of age and four in those aged 75 and over) but this did not reach statistical significance $(p=0.041)$.

One hundred necropsies were performed by trainees and 87 by trained (consultant) pathologists. There was no difference in the rate of recording unexpected findings between these two groups $(38.8 \%$ in the trainee group $v$ $41.1 \%$ in the trained group).

The mean period of in-hospital stay was 10.1 days (range $<24$ hours to 87 days; median five days). This compared with a mean in-hospital stay of 8.8 days in the non-necropsied group (NS). Forty five cases were inpatients for less than one day but these cases had been assessed sufficiently, some at previous hospital visits, for the clinicians to have a working diagnosis and formulate a treatment plan. Of these, $51 \%$ had a major unexpected finding. This compared with a rate of $36 \%$ in those with an inpatient stay of greater than one day. For an in-hospital stay of less than five days there was a $48 \%$ rate of unexpected findings which compared with a rate of $31 \%$ for those with an inpatient stay of six or more days. No significance or trend could be established between length of inhospital care and undiagnosed disease (best $p$ $=0.070$ for a stay of less than 24 hours). It may be possible that the lack of a significant relation between duration of in-hospital treatment and unexpected findings may be due to either an inadequate sample size or our protocol of specifically excluding cases where no clinical cause of death was proposed. One hundred and twenty four cases $(66 \%)$ were referred to the coroner for a variety of reasons including short duration of in-hospital stay, self neglect, alcoholism, industrial diseases, or possible effects of drugs or poisons. Forty per cent of these contained clinically unexpected findings compared with $39 \%$ of the clinically requested necropsies. Unexpected pulmonary emboli, infections and cancer were equally represented between the two groups and death due to coronary atherosclerosis was no more common in the group referred to the coroner.

A surgical procedure had been performed on $25 \%$ of cases (group A). Thirty percent of these had an unexpected major finding compared with $42 \%$ of cases who did not undergo surgery (group B) (NS). There were two unidentified cancers in group A patients, one perforated bowel with a missed colon cancer following colonoscopy and one missed malignant retroperitoneal lymphoma following a laparotomy. Other unexpected findings following laparotomy included two cases of pancreatitis, one of ascending cholangitis and one case of pneumonia mimicking peritonitis. There were five deaths due to undiagnosed myocar- 
Table 2 Clinical specialty, necropsy rate and incidence of unexpected findings

\begin{tabular}{lllll}
\hline Clinical specialty & $\begin{array}{l}\text { Mean age } \\
\text { (years) }\end{array}$ & $\begin{array}{l}\text { No. of } \\
\text { necropsies }\end{array}$ & $\begin{array}{l}\text { Necropsy } \\
\text { rate (\%) }\end{array}$ & $\begin{array}{l}\text { Unexpected } \\
\text { findings (\%) }\end{array}$ \\
\hline Medical & 70.2 & 52 & 19 & 46 \\
Surgical & 75.8 & 47 & 40 & 40 \\
ITU/CCU & 70.0 & 20 & 44 & 25 \\
Geriatrics & 80.4 & 33 & 9 & 37 \\
Renal/urology & 70.2 & 25 & 25 & 56 \\
Oncology & 64.3 & 10 & 13 & 20 \\
Obstetrics and gynaecology & 36.0 & 1 & 50 & 0 \\
\hline
\end{tabular}

dial infarctions and three postoperative pulmonary emboli.

There was no statistical correlation between necropsy requesting practice and the incidence of unexpected findings and no trend could be identified-that is, those specialties with a higher necropsy request rate were as likely to have unexpected causes of death as specialties with a low request rate (table 2 ).

\section{Discussion}

The value of the necropsy as the yardstick of clinical practice and as a vehicle of audit has been summarised in the report The Autopsy and Audit of the Joint Working party of the Royal Colleges. ${ }^{22}$ The Royal Colleges recommend an additional $10 \%$ sampling of general hospital deaths. This may be desirable in assessing the true incidence of unrecognised disease as currently all postmortem examinations are selected, either by clinicians to clarify specific clinical points or differential diagnosis, or by referral to the coroner to determine the cause of death. Despite our inability to establish factors to predict unexpected necropsy findings, these may exist in the clinical subconscious. However, despite the free availability of this report there has been little advance on the goal of a universal random $10 \%$ necropsy rate. It is only when this $10 \%$ is established, will it become clear whether instinctive factors are at work.

There has been constant debate as to the benefit of a high necropsy rate with most correspondents adopting a protagonist stance. However, is the mere fact that a procedure yields information justification for that procedure to be performed more often? This is especially relevant in the current climate of cost containing medical practice. ${ }^{26}$ To justify an increase in necropsy numbers for audit it must be shown first that clinical practice and patients benefit from these unexpected findings. Disquiet has also been expressed at the many and varied ways in which clinical and postmortem correlations are recorded ${ }^{27}$ and direct correlation between studies is probably not valid as no convention prevails. Some assess the presence of unexpected major and minor findings irrespective of the effect these had on the cause and manner of death. ${ }^{1828}$ Others record discrepancies between the clinical and the pathological cause of death ${ }^{20} 29$ and a third method is to record the incidence of clinically significant unsuspected disease that contributed to death. ${ }^{24}{ }^{25}$ We used the latter method to assess the outcome as we feel the detection of such unexpected pathology is the foremost role of the necropsy.
The necropsy rate in this study is about average for most hospitals. It has been stated that currently the necropsy rate is rarely above $25 \%$ in general hospitals ${ }^{30}$ and the range and nature of disease found is comparable with other series.

It is interesting that in our series increasing age does not carry an increased incidence of clinically unsuspected pathology. Only one paediatric series reproduced this finding, ${ }^{18}$ whereas three other necropsy studies (one general, one paediatric and one geriatric) all found a correlation between increased age and unexpected findings. ${ }^{4132}$ Sex of the deceased, ${ }^{32}$ length of in-hospital stay ${ }^{18}$ and clinical specialties $^{32}$ have all been demonstrated to have no effect on unexpected necropsy findings by others as well as by us. Interestingly, there is little in the literature to support or refute our observation that necropsy request rates and the preceding history of surgery also have little effect on the incidence of unexpected findings. ${ }^{33}$ These may be important observations. Firstly, they counter the surgeons' claim that because they have operated they understand the cause and mechanism of death: in four cases in our series laparotomy failed to identify notable abdominal pathology, and, secondly, it does not support the conviction that physicians who request necropsies may be more professional ${ }^{35}$; in our study they seem to have a similar frequency of unrecognised pathology as specialties that have low necropsy rates.

The necropsy has an extraordinary position in medical science and like all other medical disciplines it is evolving. In previous centuries the necropsy was central to the understanding of anatomy. In the first half of this century the necropsy was an important tool in experimental investigation, the discovery of diseases, and the identification and correlation of known clinical entities with abnormalities of particular cells, tissues, or organs. Currently, the necropsy is in decline in terms of numbers performed, clinical interest, the number of expert and interested pathologists and erratic support from the medical community. Simultaneously, its perceived relevance to teaching has decreased noticeably. ${ }^{36}$

The necropsy still has relevance in the 20th century for correlating pathophysiological processes with anatomical lesions and demonstrating important clinically unexpected findings. The presence of a clinically unexpected finding at necropsy must in no way indicate substandard medical care as this finding is as frequent in those hospitals that may be perceived as centres of excellence. ${ }^{37}$

Currently, most necropsies are selected by clinicians on clinical merit alone and generally to answer specific clinical concerns; this seems to be a reasonable practice as no factors have emerged from our study to permit selection of cases to improve detection of clinically unsuspected disease. On the basis of the necropsy being a mechanism of disease surveillance therefore, as long as each hospital has an adequate necropsy rate is there any need to randomly select an additional $10 \%$ for necropsy? Until there is clear evidence that the 
current practice of patient selection is anything more than random, and that the detection of unexpected findings at necropsy is of clinical value, selection of an additional $10 \%$ of deaths for postmortem examination runs the real risk of increasing the workload without any discernable benefit in terms of clinical knowledge gained.

1 Cabot R. Diagnostic pitfalls identified during a study of three thousand autopsies. $7 A M A$ 1912;59:2295-8.

2 Grundmann E, Menke G. Autopsy diagnosis versus clinical diagnosis, particularly in malignant disease. Comparison of two periods: $1961-70$ and 1978-87. IARC Sci Pub 1991;112:81-90.

3 Heasman M, Lipworth L. Accuracy of certification of cause of death. London: HMSO, 1966

4 Veress B, Alafuzoff I. A retrospective analysis of clinical diagnoses and autopsy findings in 3,042 cases during two different time periods. Hum Pathol 1994;25:140-5.

5 Waldron $H$, Vickerstaff L. Necropsy rates in the United Birmingham Hospitals. BMF 1975;2:236-240.

6 Carvalho F, Widmer M, Cruz M, Palomo V, Cruz C. Clinical diagnosis versus autopsy. Bull Pan Am Health Organ $1991 ; 251: 41-6$

7 Olle-Goig J, Canela-Soler J. The value of the autopsy in a rural hospital of Haiti. Trop Doct 1993;23:52-4.

8 Shanks J, Anderson N, McCluggage G, Toner P. Use of the autopsy in Northern Ireland and its value in perioperative deaths. IARC Sci Pub 1991;112:115-24.

9 Di Furia L, Piga A, Marmili S, Breccia R, Rubini C, Beltrami CA, et al. The value of necropsy in oncology. Eur f Cancer 1991;27:559-61.

10 Kajiwara J, Zucoloto S, Manco A, Muccillo G, Barbieri M. Accuracy of clinical diagnoses in a teaching hospital: Accuracy of clinical diagnoses in a teaching hospital

11 Sarode V, Datta B, Banerjee A, Banerjee CK, Joshi K, Bhusnurmath $\mathrm{B}$, et al. Autopsy findings and clinical diagnoses: review of 1,000 cases. Hum Pathol 1993;24:194-8.

12 Modelmog D, Rahlenbeck S, Trichopoulos D. Accuracy of death certificates: a population-based, complete-coverage, one-year autopsy study in East Germany. Cancer Causes Control 1992;3:541-6.

13 Boldy D, Jones C, Matthews H, Edwards C. Deaths and necropsies in a thoracic unit. Thorax 1993;48:284-6.

14 Burke M, Aghababian R, Blackbourne B. Use of autopsy results in the emergency department quality assurance plan. Ann Emerg Med 1990;19:363-6.

15 Gloth F, Burton J. Autopsies and death certificates in the chronic care setting. f Am Geriatr Soc 1990;38:151-5.

16 Harris M, Blundell J. Audit of necropsies in a British district general hospital. F Clin Pathol 1991;44:862-5.
17 Koszyca B, Moore L, Toogood I, Byard RW. Is postmortem examination useful in pediatric oncology? Pediatr Pathol 1993;13:709-15.

18 Stambouly J, Kahn E, Boxer R. Correlation between clinical diagnoses and autopsy findings in critically ill children. Pediatrics 1993;92:248-51.

19 Britton M. Diagnostic errors discovered by autopsy. Acta Med Scand 1974;196:203-13.

20 Mosquera D, Goldman M. Surgical audit without autopsy: tales of the unexpected. Ann R Coll Surg Eng 1993;75:115-17.

21 Teo C. A study of coroner's cases from hospitals: a comparison of autopsy and clinical diagnosis. Ann Acad Med Singapore 1993;22:3-7.

22 Royal College of Pathologists, the Royal College of Physicians of London and the Royal College of Surgeons of England. The autopsy and audit. The Report of the Joint Working Party of the Royal College of Pathologists, the Royal College of Physicians of London and the Royal College of Surgeons of England. London: The Royal College lege of Surgeons of E
of Pathologists, 1991.

23 Goldman L, Sayson R, Robbins S, Cohen L, Bettmann M, Weisburg M. Diagnostic advances vs. the value of the autopsy, 1912-1980. Arch Pathol Lab Med 1984;108:501-5.

24 Schned A, Mogielniki R, Stauffer M. A comprehensive quality assessment program on the autopsy service. $A m \mathcal{F}$ Clin Pathol 1986;86:133-8.

25 Harrison $M$, Hourihane D. Quality assurance programme for the necropsy. F Clin Pathol 1989;42:1190-3.

26 Wells R. Diagnostic yield of the autopsy. $N$ Engl $7 \mathrm{Med}$ 1988;319:1095-6.

27 Saracci R. Is necropsy a valid monitor of clinical diagnosis performance? BMF 1991;303:898-900.

28 Russell G, Berry P. Postmortem audit in a paediatric cardiology unit. $\mathcal{F}$ Clin Pathol 1989;42:912-18.

29 Cameron H, McGoogan E. A prospective study of 1152 hospital autopsies. I. Inaccuracies in death certification. $\mathcal{F}$ Pathol 1981;133:273-85.

30 Cameron $\mathrm{H}$. Future of the hospital autopsy. Br $\mathcal{f}$ Hosp Med 1989;41:335.

31 Poli L, Pich A, Zanocchi M, Fonte G, Bo M, Fabris F Autopsy and multiple pathology in the elderly. Gerontology 1993:39:55-63.

32 Mitchell $M$. Interdepartmental quality assurance using coded autopsy results. Mod Pathol 1993;6:48-52.

33 Barendregt W, de Boer H, Kubat K. Autopsy analysis in surgical patients: a basis for clinical audit. Br $\mathcal{F}$ Surg 1992;79; 1297-9.

34 Barendregt W, de Boer $\mathrm{H}$, Kubat $\mathrm{K}$. The results of autopsy of patients with surgical diseases of the digestive tract. Surg of patients with surgical diseases of

35 Gloth F, Burton J. Geriatric autopsies: it's time to get involved. Geriatrics 1990;45:72-7.

36 King D. Potential of the autopsy. Arch Pathol Lab Med 1984; 108: 439-43

37 Lansfield C, Chren M, Myres A, Geller R, Robbins S, Goldman L. Diagnostic yield of the autopsy in a university hospital and a community hospital. $N$ Engl $\mathcal{f ~ M e d}$ 1988;318: 1249-54. 